\title{
A NOTE ON THE USE OF HORSE HAIR SUTURES FOR THE CONJUNCTIVA
}

BY

Percival J. HaY

SHEFFIELD

I HAVE found horse hair extremely useful for closing the wound after inserting the glass globe in a Frost-Lang operation. No knots are required. It keeps the wound firmly closed in virtue of its rigidity, while it does not bunch up the conjunctiva like a silk purse-string suture.

A good grip is taken of the conjunctiva beyond one end of the wound (Fig. 1), and the horse hair on a Mersuture needle passed from below upwards, then in and out along the lips of the wound,

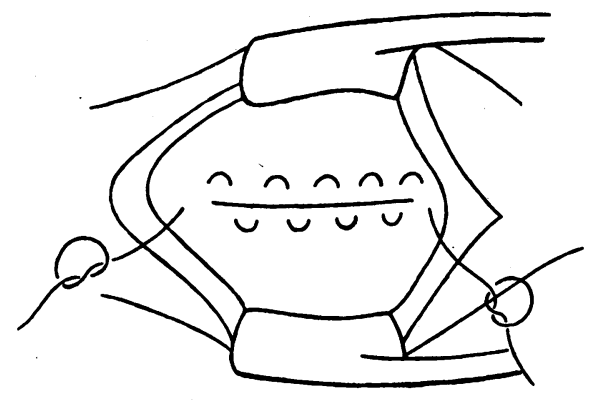

FIG. 1.

Horse hair suture for closing the wound after a Frost-Lang operation.

keeping about 3 to $4 \mathrm{~mm}$. from the margin, finally down and out beyond the other end of the wound. The suture is now drawn taut and a loop made at each end, placing it so as to lie outside the lids when the eye is closed. The loops prevent the suture from being pulled out accidentally. Their position can be adjusted by placing the point of a closed artery forceps in the loops and running them to their proper position. When the wound has healed, and the time has come to remove the suture, i.e., in about a week, all that is required is to cut one end close to the conjunctiva, pull quickly at the other end, and the suture is out almost before the patient is aware of it.

In times gone by I used to suture the recti or Tenon's capsule separately with catgut, and then the conjunctiva with silk. The cosmetic appearance and the movement subsequently imparted to the artificial eye is, however, quite as good by the method just described as by the older time-consuming one. In addition, if 
the size of the glass globe has been properly judged, it will stay in because a broad and continuous surface of contact is secured between the lips of the wound.

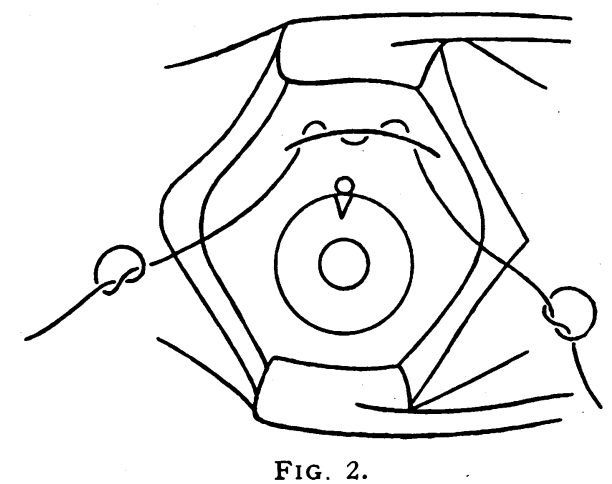

Horse hair suture for closing the conjunctival wound after trephining.

The same suture may be used with advantage for closing the wound in the conjunctiva after trephining. It is passed in and out as shown in Fig. 2, and, as in the previous operation, it is easily removed. No difficult silk knots to find and cut! No cocaine necessary to assist in their removal.

\section{THE PATHOLOGY OF SCLERAL PLAQUES \\ Report of five cases of degenerative plaques in the sclera mesially, one studied histologically}

BY

Arthur M. Culler, M.D.

DAYTON, OHIO

UNDER the heading, "Bilateral mesial superficial deficiency of the sclera," Basil Graves ${ }^{1,2}$ has recently described two cases of this disease. I have encountered this condition (which on casual observation I thought might be a hyaline change in the insertion of the internal rectus muscle) and found that the edge of the lesion lay approximately $3 \mathrm{~mm}$. behind the mesial conjunctival limbus. It presented the appearance under the slit-lamp of a minute squared hole in the outer layers of the sclera through which the underlying ciliary body could be seen. A slightly congested conjunctiva was neither elevated nor depressed over the lesion. 